February 2008

\title{
The yin and yang of FcY receptors in ITP
}

Steven E. McKenzie

Thomas Jefferson University

Follow this and additional works at: https://jdc.jefferson.edu/medfp

Part of the Medical Genetics Commons

Let us know how access to this document benefits you

\section{Recommended Citation}

McKenzie, Steven E., "The yin and yang of Fcy receptors in ITP" (2008). Department of Medicine Faculty Papers. Paper 32.

https://jdc.jefferson.edu/medfp/32

This Article is brought to you for free and open access by the Jefferson Digital Commons. The Jefferson Digital Commons is a service of Thomas Jefferson University's Center for Teaching and Learning (CTL). The Commons is a showcase for Jefferson books and journals, peer-reviewed scholarly publications, unique historical collections from the University archives, and teaching tools. The Jefferson Digital Commons allows researchers and interested readers anywhere in the world to learn about and keep up to date with Jefferson scholarship. This article has been accepted for inclusion in Department of Medicine Faculty Papers by an authorized administrator of the Jefferson Digital Commons. For more information, please contact: JeffersonDigitalCommons@jefferson.edu. 


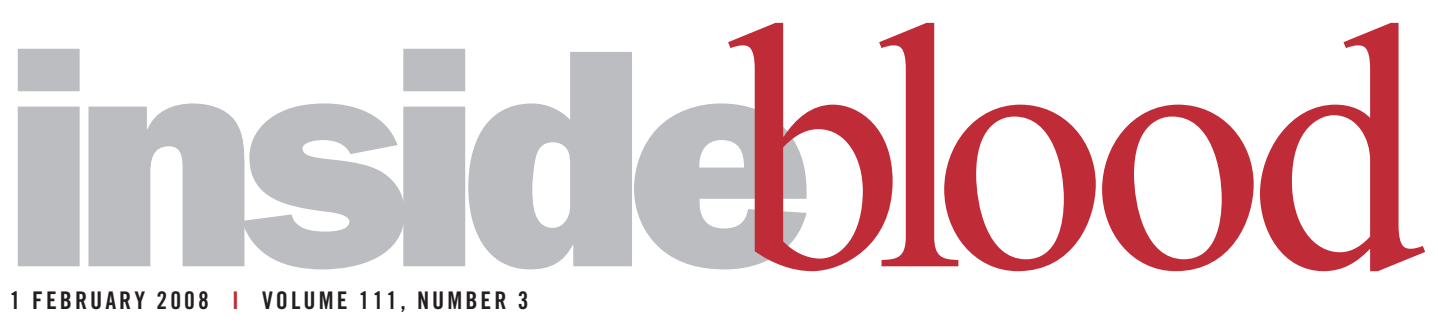

- CLINICAL OBSERVATIONS

Comment on Breunis et al, page 1029

\section{The yin and yang of $\mathrm{Fc} \gamma$ receptors in ITP}

\section{Steven E. McKenzie cardeza foundation for hematological RESEarch, thOMas Jefferson UNIVERSITY}

In this issue of Blood, Breunis and colleagues examine the role of genetic variation in the human $\mathrm{Fc}$ receptors for $\mathrm{IgG}$ in the susceptibility to idiopathic thrombocytopenic purpura (ITP).

T he Fc $\gamma$ receptors contribute to the susceptibility to autoimmune diseases such as ITP in several ways: (1) they modulate dendritic cell antigen processing and presentation, (2) they modulate antibody production by $\mathrm{B}$ cells, and (3) they participate in effector cell functions, such as phagocytosis, antibodydependent cellular cytotoxicity, and mediator release. The key finding in recent years has

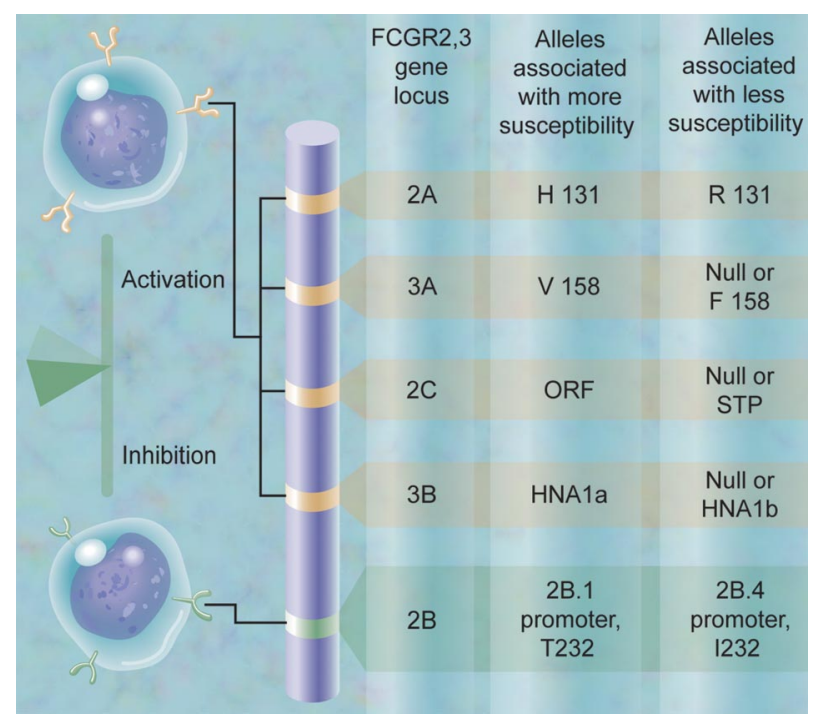

The SNP and CNV alleles in the human FCGR2,3 gene locus at chromosome 1q23 that contribute to susceptibility to autoimmune disease are shown schematically, including the genetic variation in FCGR2C in the study on ITP by Breunis et al. (The alleles are defined in that article.) The balance of activation and inhibition contributes to greater or lesser susceptibility to autoimmune disease. been the appreciation that the activating $\mathrm{Fc} \gamma$ receptors, encoded by FCGR2A, -2C, -3A, and $-3 \mathrm{~B}$, compete with the inhibitory Fc $\gamma$ receptor, encoded by FCGR2B, to determine cellular responses to immune complexes and antibody-coated cells.

The work by this team, led by Dr Taco Kuijpers, is noteworthy for several reasons. First, the authors have achieved a technical tour-de-force, developing multiplex ligationdependent polymerase amplification assays (MLPAs) to simultaneously identify both single nucleotide polymorphisms (SNPs) and copy number variations (CNVs) in the 5 gene locus containing the so-called low-affinity Fc receptors for $\mathrm{IgG}$ : FCGR2A, -2B, -2C, -3A, and $-3 \mathrm{~B}$. These genes are highly homologous, and genetic studies of this region are notoriously difficult. The authors typed 8 biologically significant variations at the same time. Second, they discovered a new CNV for the FCGR3A gene. Third, their assays combined the ability to identify an im- portant FCGR2C SNP (ORF, open reading frame, versus STP, stop codon) with the ability to detect deletion or duplication of a block containing the adjacent FCGR2C and FCGR3B genes. Finally, in a study comparing the frequency of these FCGR2,3 gene variations in healthy individuals versus in children and adults with ITP, analyzed separately and as a group, they discovered a significant overrepresentation of the FCGR2C ORF allele in individuals with ITP. The team convincingly confirmed the work by Ernst, Herberman, and colleagues $^{1}$ that the FCGR2C genotype determines the phenotype, with respect to protein expression and function. Since FCGR2C is an activating receptor in monocytes/macrophages and natural killer (NK) cells, the findings are consistent with the current paradigm in the field that the balance of activating versus inhibitory Fc $\gamma$ receptors contributes to susceptibility to autoimmune disease (see figure).

Where does the field go from here? These 8 genetic variations are not in linkage disequilibrium, but individuals will be endowed in this region of chromosome 1q23 with a haplotype of FCGR2,3 SNPs and CNV that can influence the susceptibility to ITP and other auto- or allo-immune disorders. In the figure, the hypothesized set of alleles conferring greater susceptibility is contrasted to the set conferring lesser susceptibility. Further technical advances and larger numbers of patients and controls, especially those of diverse ethnic groups, will be needed to test the potential clinical value of assaying genetic differences in susceptibility. Equally exciting, however, is the prospect that these genetic variations contribute to differences in the response to therapeutics for ITP. Modulation of Fc $\gamma$ receptor activating and inhibitory functions are mainstays of ITP treatment. ${ }^{2-4}$ We may even go so far as to link responses to a broader set of antibody therapeutics for human disease to the haplotype of FCGR2,3 genetic variations.

Conflict-of-interest disclosure: The author declares no competing financial interests. 


\section{REFERENCES}

1. Ernst LK, Metes D, Herberman RB, Morel PA. Allelic polymorphisms in the FcgammaRIIC gene can influence its function on normal human natural killer cells. J Mol Med. 2002;80:248-257.

2. McKenzie SE. The biology and treatment of ITP: what's next? Blood. 2003;102:417.
3. Crow AR, Song S, Siragam V, Lazarus AH. Mechanisms of action of intravenous immunoglobulin in the treatment of immune thrombocytopenia. Pediatr Blood Cancer. $2006 ; 47: 710-713$

4. Nimmerjahn F, Ravetch JV. The antiinflammatory activity of IgG: the intravenous IgG paradox. J Exp Med. 2007;204:11-15.

\section{Shear elegance: regulation of thrombus growth by shear stress}

William E. Hobbs II and José A. López PUget sound BLOOd CENTER

A new study by Shida et al provides an elegant explanation for how vessel wall injuries are repaired without occluding the vessel.

T he hemostatic repair of damaged endovasculature resembles an intricate symphony orchestrated by platelets and a variety of plasma proteins, all tightly regulated to prevent lumen occlusion and thromboembolism. One key player in this symphony, von Willebrand factor (VWF), functions to bridge exposed collagen on damaged subendothelial surfaces to receptors on circulating platelets and to bridge platelets to each other as the thrombus grows. ${ }^{1}$ Its ability to perform both tasks relates to the size of its multimers and exposure to shear stress.

VWF is synthesized in only 2 cell types, endothelial cells and megakaryocytes, and is released constitutively by endothelial cells or from storage granules of endothelial cells or platelets in response to secretagogues. The VWF newly released from granules is enormous (hence the designation ultra-large VWF or ULVWF) and hyperadhesive. ${ }^{2}$ ADAMTS13 rapidly converts ULVWF to smaller and less adhesive species through proteolytic cleavage at the peptide bond Y1605-M1606 within the A2 domain. Proteolysis is enhanced by shear stress ${ }^{3}$ and by platelet binding. ${ }^{4}$ Shear stress is also one of the variables that enhances the binding of plasma VWF to platelets. ${ }^{5}$ In this issue of Blood, Shida and colleagues provide a fascinating explanation for how shear stress can facilitate platelet thrombus formation while simultaneously limiting thrombus growth. In a simple and elegant experiment, the investigators examined the contribution of ADAMTS13 activity to the growth of platelet thrombi at different shear stresses. They perfused blood over a collagen-coated surface in a perfusion chamber and used 2 very valuable monoclonal antibodies to probe ADAMTS13 functions: one that blocked ADAMTS13 activity and one that bound only after ADAMTS13 cleaved VWF (N10). As expected, ADAMTS13 blockade increased thrombus growth rate and volume concurrent with decreased N10 antibody binding. When ADAMTS13 was unopposed, N10 binding increased, indicating increased VWF cleavage in the smaller thrombi that resulted, a phenomenon that became more pronounced with increased shear stress. N10 staining also increased with increased distance from the base of the thrombus, being greatest at the surface. Extrapolated to a high-shear mural thrombus in vivo, these results suggest that as shear stress increases by progressive luminal narrowing, so does cleavage of VWF by

ADAMTS13. Thus, not only does ADAMTS13 control VWF reactivity by reducing the size and reactivity of its ultra-large forms,

\section{- TRANSPLANTATION}

Comment on Syrjala et al, page 989

Gerard Socié HOSPITAL SAINT LOUIS quent late effect ever reported. matopoietic cell transplantation (HCT) is increasing rapidly; worldwide, more than 45000 patients receive HCT each year. $\mathrm{Pa}-$ he number of long-term survivors of he- it also acts on the form of VWF normally found in plasma as it participates in the buildup of thrombi.

These findings suggest a mechanism that allows repair of vessel wall defects without the repair process completely occluding the vessel. They also provide further insight into the pathophysiology of the most extreme manifestation of ADAMTS13 deficiency: thrombotic thrombocytopenic purpura (TTP). In TTP, ADAMTS13 deficiency may have 2 important but distinct roles: first, it allows ULVWF to linger on the vessel wall and bind the first layer of platelets; and second, it is unable to prevent platelets that attach to the thrombus subsequently from completely occluding the vessel.

This elegant study also demonstrates that experiments need not be particularly complicated in nature or technologically difficult to provide mechanistic insights; they just have to be carefully considered.

Conflict-of-interest disclosure: The authors declare no competing financial interests.

\section{REFERENCES}

1. Ruggeri ZM. The role of von Willebrand factor in thrombus formation. Thromb Res. 2007;120 Suppl 1:S5-9. 2. Arya M, Anvari B, Romo GM et al. Ultralarge multimers of von Willebrand factor form spontaneous highstrength bonds with the platelet glycoprotein Ib-IX complex: studies using optical tweezers. Blood. 2002;99:39713977

3. Tsai HM, Sussman II, Nagel RL. Shear stress enhances the proteolysis of von Willebrand factor in normal plasma. Blood. 1994;83:2171-2179.

4. Shim K, Anderson PJ, Tuley EA, Wiswall E, Sadler JE. Platelet-VWF complexes are preferred substrates of ADAMTS13 under fluid shear stress. Blood. Prepublished on September 27, 2007, as DOI 10.1182/blood-2007-05093021

5. Moake JL, Turner NA, Stathopoulos NA, Nolasco LH, Hellums JD. Involvement of large plasma von Willebrand factor (vWF) multimers and unusually large vWF forms derived from endothelial cells in shear stress-induced platelet aggregation. J Clin Invest. 1986;78:1456-1461.

\section{Sexuality in long-term survivors}

In this issue of Blood, Syrjala and coworkers highlight that sexual recovery in longterm survivors after allogeneic stem-cell transplantation may well be the most fre-

tients with leukemias who survive without recurrent malignancy for 2 years after allogeneic HCT currently have an $89 \%$ probability of surviving for 5 or more years. Research on 